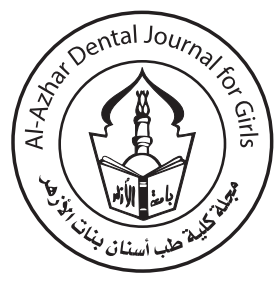

\title{
The Effect of Post Dam and Border Replacement by a Flexible Acrylic on Denture Retention
}

\author{
Sara H. Kadry ${ }^{*}$, Mohamed E. Sanad ${ }^{2}$, Hala M. Gamal El-Deen ${ }^{3}$
}

Codex : 03/21.04

azhardentj@azhar.edu.eg

http://adjg.journals.ekb.eg

DOI: $10.21608 /$ adjg.2021.22696.1217

Restorative Dentistry

(Removable Prosthodontics, Fixed

Prosthodontics, Endodontics, Dental Biomaterials, Operative Dentistry)

\section{KEYWORDS}

Complete denture,

Flexible acryl, Retention.

\begin{abstract}
Purpose: to study the effect of using thermo-elastic acrylic resin borders and postdam on retention of conventional heat cured acrylic resin. Material and Methods: Fifteen completely edentulous patients were selected from the out-patient Clinic of the Removable Prosthodontics Department; Faculty of Oral and Dental Medicine for Girls, Al- Azhar University. On the day of the delivery each patient received maxillary and mandibular complete dentures made of conventional heat cured acrylic resin (Heat cured acrylic resin, Vertex-B. V, Netherlands). A duplicate cast was made for the maxillary complete denture. 15 patients were divided into 3 groups, 5 patients each. The first group wore the conventional heat cured acrylic complete dentures unchanged all the time, for the second group 2-3mm of the entire maxillary denture borders were removed and replaced with the flexible denture base material (Versacryl), without replacing the post dam area, while for the third group only the post dam area was replaced by the flexible denture base material (Versacryl). Results: Pair-wise comparisons between the groups revealed that borders group showed the statistically significant highest mean retention value. Conclusion: Thermo-elastic heat cured acrylic resin (Versacryl) modified dentures exhibit more retention than that of the conventional heat cured acrylic denture.
\end{abstract}

\section{INTRODUCTION}

In spite of the decrease in the rate of complete edentulism, due to implants and fixed prosthesis, the need for complete dentures will continue $^{(1-3)}$. There is a probability for problems to arise after insertion of complete dentures. The most frequent complaints of patients wearing

- Paper extracted from Master thesis titled "The Effect of Post Dam and Border Replacement by a Flexible Acrylic on Denture Retention."

1. Demonstrator at Misr International University

2. Professor of Removable Prosthodontics Faculty of Dental Medicine for Girls, AL-Azhar University, Cairo, Egypt

3. Professor of Removable Prosthodontics Faculty of Dental Medicine for Girls Al-Azhar University, Cairo, Egypt

* Corresponding author email: salsaa_89@hotmail.com 
complete dentures are mucosal irritation, insufficient retention and stability, food accumulation under the dentures, masticatory inefficiency, unattractive appearance $^{(4)}$.

The most commonly used denture base material is Poly methyl methacrylate, since its introduction in 1937. However, some problems had been encountered during its use, such as presence of unilateral or bilateral undercuts that complicate the fabrication of denture prosthesis ${ }^{(2,5)}$.

Researches have been carried out to enhance the quality of complete denture retention through using flexible dentures. Flexible dentures enhance denture retention by close adaptation to the supporting tissues and engagement of undercuts ${ }^{(6,7)}$. They provide comfort, excellent aesthetics and better denture adaptation and complete biocompatibility ${ }^{(2,7,8)}$.

"Versacryl" is a multipurpose thermo-elastic acrylic resin material that was introduced in the last decade. It allowed prosthodontists to improve retention, esthetics and comfort for the patient. It enhanced adaptation to tissue through utilizing existing undercuts without altering the position of the artificial teeth, hence the occlusion of the prosthesis $^{(2,9)}$.

Each Versacryl laboratory kit contains softener monomer liquid, hardener monomer liquid, and 2 polymer powder (Clear and Pink). Any part of the denture is adjustable only using warm water. It can be used to replace clasps, utilize undercuts, produce repeatable thermo-liners, thus enhancing comfort and retention. It is also used as a stress breaker, shock absorber for implants, flexible denture flanges and tissue conditioning material ${ }^{(10,11)}$. Versacryl has a compressive or cushioning action. When used as a clasp arm, under functional load, it can absorb the applied stress and minimizes the distortion of the supporting tissues and the fatigue of the masticatory muscles ${ }^{(12)}$.

In addition, thermoplastic resin clasps are very hygienic and don't easily stain as they are non-porus and are easily cleaned preventing the adherence of debris to the clasp ${ }^{(13)}$.

\section{MATERIAL AND METHODS}

Fifteen completely edentulous patients were selected from the outpatient Clinic of the Removable Prosthodontic Department; Faculty of Dental Medicine for Girls, Al- Azhar University. They were divided into three groups. The age range of selected patients was from 55-60 years and were free from any systemic diseases. Only motivated patients participated in the study after signing an informed consent. Each patient received maxillary and mandibular complete dentures made of conventional heat cured acrylic resin (Heat cured acrylic resin, Vertex-B. V, Netherlands).

The retention of all 15 maxillary complete dentures was measured after one week from delivery. In the first group, the conventional acrylic denture was delivered and recalled after 1 week, 2 weeks, 3 weeks and again after 3 months for retention evaluation. While for the second and third groups retention was measured after 1 week from delivery of conventional denture then modification was carried out and the modified denture was returned to the patient. After that they were recalled for measuring the retention of the modified maxillary denture after 1 week, 2 weeks and then again after 3 months.

A digital force meter was used to measure denture resistance to vertical displacement by applying a pulling force on a metal hook located in the geometric center of each maxillary conventional denture and the mean retention is presented in Newton $(\mathrm{N})^{(2)}$.

\section{Measuring the retention of maxillary denture:}

Maxillary denture was inserted inside patient mouth and was allowed to remain inside his/ her mouth for a seating time three minutes. Then the hook of the digital force meter was inserted, and pulled downward, reading was recorded. The procedure was repeated six times. 
Readings were converted from Kilogram to Newton. Data were collected, calculated, tabulated and statistically analyzed.

\section{Duplication Procedures}

Stone cast for the upper denture bearing area was obtained by pouring dental stone (Dental stone hard type) in the upper denture after the undercuts were blocked. Then, a uniform layer of putty condensation silicone was applied to the polished surface of the denture and to the teeth. Then the upper half of the flask was placed in position. After the stone has set, the two halves of the mold were separated and the denture was removed ${ }^{(14)}$.

\section{Construction of Thermo-elastic resin modified denture}

Modification of the upper denture was performed by cutting the denture borders or post dam area using stone. All undercuts of the polished surface of the maxillary denture base were blocked except the borders. Separating medium was applied on the denture and the cast and flasking then carried out.

Versacryl was packed against monomer (hardener) - primed acrylic denture area from which the resin had been removed, flask was closed, pressed and procedure were completed as for conventional heat cured resin as it did not require any special equipment. Deflasking and finishing were accomplished.

Before insertion of the dentures with flexible borders or post dam area, the maxillary denture was immersed in hot water bath for 5 mins to soften the flexible part, so they can be easily adjusted to adapt into the undercut areas ${ }^{(15)}$.

The materials used are illustrated in the table of materials (Table 1).

Table (1): Table of materials

\begin{tabular}{|c|c|c|c|c|}
\hline Material name & Description & Specifications & Manufacturer & Batch number \\
\hline Vertex B. V & $\begin{array}{l}\text { Rapid heat curing } \\
\text { acrylic }\end{array}$ & $\begin{array}{l}\text { Powder: PMMA } \\
\text { Liquid: MMA, DMA }\end{array}$ & $\begin{array}{l}\text { Vertex-Dental, } \\
\text { Netherlands }\end{array}$ & $\begin{array}{l}\text { Powder: Lot } \\
\text { XT382P02 } \\
\text { Liquid: } \\
\text { XT381L02 }\end{array}$ \\
\hline Versacryl & $\begin{array}{l}\text { Powder } \\
\text { Liquid monomers: } \\
\text { a. Softener } \\
\text { b. Hardener }\end{array}$ & $\begin{array}{l}\text { Powder: Polymethyl methacrylate (PMMA) } \\
\text { Liquid: } \\
\text { a. Softener : Plasticized methacrylate } \\
\text { monomer (Dibutyl Phthalate, Dioctyl } \\
\text { Phthalate, Methyl Methacrylate, n- } \\
\text { Butyl Methacrylate, Ethylene Glycol } \\
\text { Dimethacrylate and N,N-Dimethyl-P- } \\
\text { Toluidine) } \\
\text { b. Hardener: Methacrylate monomer } \\
\text { (Methyl Methacrylate and Ethylene Glycol } \\
\text { Dimethacrylate) }\end{array}$ & $\begin{array}{l}\text { Keystone industries } \\
\text { USA }\end{array}$ & $\begin{array}{l}\text { Powder: } 4002 \\
\text { Liquid: } \\
\text { 122280f }\end{array}$ \\
\hline Dental stone & Hard type IV & CAM-base & $\begin{array}{l}\text { Dentona AG, } \\
\text { Dortmund, Germany }\end{array}$ & 10300206 \\
\hline Digital force meter & $\begin{array}{l}\text { Ametex, DFX II } \\
\text { series digital force } \\
\text { gauge }\end{array}$ & SS-DFX II series & $\begin{array}{l}\text { ISO } 9001 \\
\text { manufacturer }\end{array}$ & $\begin{array}{l}\text { PCE-CS 300- } \\
\text { ICA }\end{array}$ \\
\hline $\begin{array}{l}\text { Putty condensation } \\
\text { silicone }\end{array}$ & $\begin{array}{l}\text { Labosil silicone } \\
\text { putty }\end{array}$ & Super high shore A, hardness 90 & Protechno, Spain & 94807768 \\
\hline
\end{tabular}




\section{RESULTS}

Descriptive statistics showing mean, standard deviation, range (minimum-maximum) and results of ANOVA test for comparison between retention of the three groups as function of follow up time are summarized in (Table 2 and Fig 1).

Table (2) Descriptive statistics and results of ANOVA test for comparison between retention of the three groups as function of follow up time.

\begin{tabular}{|c|c|c|c|c|c|c|}
\hline \multirow{2}{*}{ Group } & \multicolumn{2}{|c|}{1 week } & \multicolumn{3}{|c|}{2 weeks } & 3 months \\
\hline & Mean (SD) & $\begin{array}{c}\text { Range } \\
\text { (mini. -maxi.) }\end{array}$ & Mean (SD) & $\begin{array}{c}\text { Range } \\
\text { (mini. -maxi.) }\end{array}$ & Mean (SD) & $\begin{array}{c}\text { Range } \\
\text { (mini. -maxi.) }\end{array}$ \\
\hline Control & $33.3(9.8)^{\mathrm{C}}$ & $(23.5-43.1)$ & $33.8(12.9)^{\mathrm{C}}$ & $(24.2-47.1)$ & $35.65(11.45)^{\mathrm{C}}$ & $(23.5-43.1)$ \\
\hline Borders & $69.8(26.9)^{\mathrm{A}}$ & (42.9-96.8) & $72.1(15.9)^{\mathrm{A}}$ & $(56.2-88)$ & $76.8(15.4)^{\mathrm{A}}$ & $(61.4-92.5)$ \\
\hline Post dam & $49.55(28.8)^{\text {В }}$ & $(15.7-83.4)$ & $57.1(27.5)^{\mathrm{B}}$ & $(26.2-88)$ & $57.4(28.9)^{\text {в }}$ & $(27.8-87)$ \\
\hline P-value & \multicolumn{2}{|c|}{$0.049 *$} & \multicolumn{2}{|c|}{$0.012 *$} & \multicolumn{2}{|c|}{$0.005 *$} \\
\hline
\end{tabular}

*: Significant at $P \leq 0.05$, Different superscripts in the same column are statistically significantly different

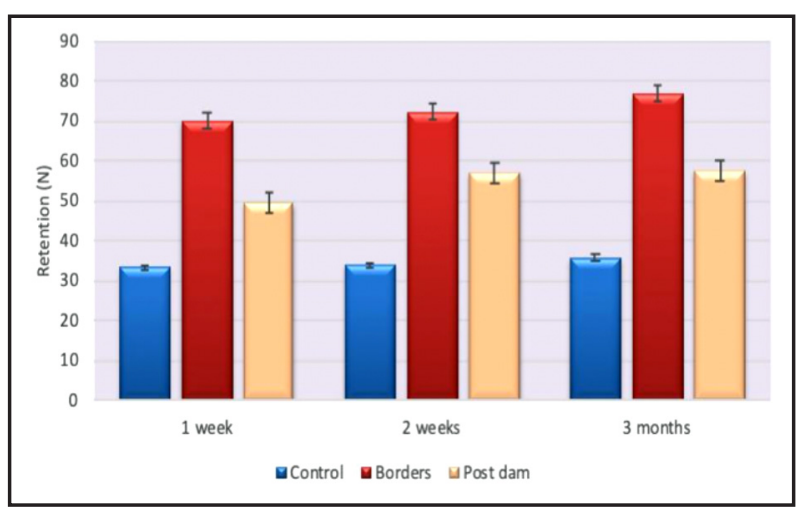

Figure (1): Column chart representing mean values for retention at different follow up times within each group

Along the entire 3 months period; there was a statistically significant difference between retention mean values of the three groups ( $P$-value $=0.049<0.05),(P$-value $=0.012<0.05))$ and $(P$-value $=0.005<0.05)$, respectively. Pair-wise comparisons between the groups revealed that borders group showed the statistically significantly highest retention mean value and post dam group showed statistically significantly lower mean value. While, the control group showed the statistically significantly lowest retention mean value.

\section{DISCUSSION}

Fifteen completely edentulous patients were selected. The age of the selected patients ranged from 50 to 65 . Very old patients, patients with abnormal salivation, patients with systemic diseases which could affect denture retention were excluded due to many factors that would complicate the treatment process such as decreased neuromuscular coordination, and reduction in the ability to sense where the mandible in relation to the maxilla (oral awareness) ${ }^{(16-18)}$.

Patients having moderately formed completely edentulous maxillary ridges with moderate palatal vault depth (U- shaped palatal vault) were only selected as this contour and shape of maxillary ridges were the most favorable for retention and lateral stability ${ }^{(19)}$.

The materials used in this study were the conventional heat cured acrylic resin, and a new material heat cured thermo-elastic acrylic resin. This new form of acrylic resin consists of a polymer powder, and the liquid monomer. The monomer is 
supplied in two forms, the softener monomer and the hardener monomer. The degree of the resultant flexibility of the finished base depends upon the ratio of the softener monomer to the hardener monomer. The mix was done according to manufacturer's instructions ${ }^{(15)}$.

The heat cured thermo-elastic acrylic resin can be finished and polished as the conventional heat cure acrylic resin. The heat cure thermo-elastic acrylic resin is composed of methyl methacrylate, which bonds chemically to the denture base ${ }^{(1,15)}$.

In vivo retention was measured using a digital force meter. To ensure accuracy and reliability of the results, all measurements should be recorded at the same position or point every time at the geometric center of the denture. Each patient was asked to sit upright in a chair with the occlusal plane of upper teeth parallel to the floor ${ }^{(20)}$.

The results of this study showed an apparent clear superiority of retention of the thermo-elastic acrylic resin "Versacryl" modified maxillary complete denture than that of the conventional heat cured acrylic resin, this may be attributed to the intimate adaptation and settling of the thermo-elastic denture to the underlying resilient mucosa ${ }^{(21)}$.

In this study, it was obvious that the retention of flexible acrylic resin "Versacryl" modified maxillary complete denture in both borders and post dam area were higher than conventional heat cured acrylic resin. Also, similar results where attained by a previous study that used the thermo-elastic lingual flanges in the construction of mandibular complete dentures which resulted in improved denture retention, compared to conventionally made dentures with acrylic resin flanges. This may be due to the physical properties of the thermo-elastic acrylic which allowed effective engagement with the lingual pouch undercut and close adaptation to the supporting tissues ${ }^{(2,22)}$.

The close adaptation and increase retention is also supported by another study that showed the correlation between adhesion and denture adaptation. It proved that the effectiveness of adhesion depends on the close adaptation of the denture to the supporting tissues ${ }^{(23)}$.

Another study proved that conventional acrylic resin assumed significantly higher water sorption than the thermo-elastic resin. Water sorption was definitely associated with some dimensional changes which explains the increase in retention of "Versacryl" at a higher rate than the conventional acrylic resin and the only slight increase in retention regarding conventional acrylic resin. These changes probably causes distortion, therefore negatively affecting denture adaptation, border seal and retention. Also, when these changes happen in postdam area, which is a critical region, slightly affecting adaptation and retention of the denture. This explains why borders showed statistically significant highest mean retention value followed by post dam ${ }^{(24)}$.

The higher retention of flexible resin modified dentures may be attributed to the property of atmospheric pressure which acts to resist the dislodging forces applied to the dentures, if the dentures have an effective seal around their borders. This is supported by a study which reported that retention due to atmospheric pressure is directly proportional to the area covered by the denture base and to the intimate peripheral seal ${ }^{(25)}$.

\section{CONCLUSION}

Within the limitations of the present study, the following conclusions were obtained. Thermoelastic heat cured acrylic resin (versacryl) modified dentures exhibit more retention than that of the conventional heat cured acrylic denture. Placing Thermo-elastic heat cured acrylic resin (versacryl) at borders significantly increased retention. Also, placing Thermo-elastic heat cured acrylic resin (versacryl) at post dam area increased retention. However it was less compared to thermo-elastic borders. 


\section{REFERENCES}

1. Elmorsy AE, Ahmed Ibraheem EM, Ela AA, Fahmy A, Nassani MZ. Do flexible acrylic resin lingual flanges improve retention of mandibular complete dentures. J Int Soc Prevent Communit Dent. 2015;5:365-71.

2. Alloush NT, Sanad ME, Kabeel SM. Evaluation of retention of a recently suggested flexible denture base material. ADJ-for Girls. 2019;6:109-13.

3. Khan SA, Rashid H, Sukkurwalla A, Naz A. Complete denture complication among patients in a teaching hospital of Karachi. JPDA. 2015;35-8.

4. Nooji, D. Post insertion problems and management in complete denture patients. Lambert Academic Publishing. 2017.

5. Alla RK, Swamy KN, Vyas R, Anusha Konakanchi A. Conventional and Contemporary polymers for the fabrication of denture prosthesis. JOADMS 2015;1:82-9.

6. Khindria SK, Mittal S, Sukhija U. Evolution of denture base materials. JIPS. 2009;9: 64-9.

7. Sultan M , Abou Ela A, Salloum M. Impact of Thermoplastic Acrylic Denture Base Versus Conventional Base on the Patient Satisfaction in Implant Supported Mandibular Overdenture: A Systematic Review. Indian Journal of Science and Technology. 2016; 9:1-4.

8. Academy of Prosthodontics. Glossary of Prosthodontics Terms. $9^{\text {th }}$ ed J Prosthet Dent. 2017;117:5.

9. Khindria SK, Mittal S, Sukhija U. Evolution of denture base materials. JIPS. 2009; 9: 64-9.

10. Donovan T.E. and Cho G.C.: Esthetic consideration with removable partial dentures, J. Calif Dent. Assoc, 2003;31:551-5.

11. Hayakawa I. Repeatable Thermo-adjustable reline using Versacryl. Elaborate Magazine. 2006; 28-9.

12. Ibraheem EMA, Nassani MZ. The effect of flexible acrylic resin on masticatory muscle activity in implant-supported mandibular overdentures: a controlled clinical trial. Electron physician. 2016;8:1752-8.
13. Eskander A, Ibrahim S, Dahaba M. Versacryl versus chrome-cobalt clasps in implant- supported partial overdentures. J Res Pract Dent. 2014;1-18.

14. Rajapur A. Duplication of complete denture using autopolymerizing acrylic resin: a review of techniques. $\mathrm{J}$ Prosthet Dent. 2011;2-11.

15. Zaki DI, Moussa AA, Abou Zeid AW. Dynamic Mechanical Thermal Analysis of a Multipurpose Thermo-Elastic Acrylic Resin With Different Softener/Hardener Monomer Ratios. AJBAS. 2012;6:695-9.

16. Kumar MV, Bhagath S, Jei JB. Historical interest of denture base materials. J Dent Sci. 2010;1:103-5.

17. Turner M, Jahangiri L, Ship JA. Hyposalivation, xerostomia and the complete denture: a systematic review. J Am Dent Assoc. 2008;139:146-50.

18. Winkler S.: Essentials of complete denture prosthodontics. $2^{\text {nd }}$ ed. Philadelphia, Saunders WB Co. 2000:202.

19. Basker R M., Davenport J. C. and Tonlin H.R.: Prosthetic treatement of edentulous patients. 2002; $4^{\text {th }}$ ed. London, 268.

20. Aqutaibi A, Abdullah M, Kaddah A. Comparison of two attachments retaining mandibular immediately loaded two implant overdentures. C.D.J. 2012; 28:1-7.

21. Jain R, Pamecha S, Jain GC. Realeff - Relevance in complete dentures. IJIET. 2012; 1:4-7.

22. Rickman LJ, Padipatvuthikul P, Satterthwaite JD. Contemporary denture base resins: Part 2. Dent Update. 2012;39: 176-8.

23. Lakhyani R, Wagdargi SS. Saliva and its importance in complete denture prosthodontics. Natl J Integr Res Med. 2012;3:122-9.

24. Takabayashi Y. Characteristics of denture thermoplastic resins for non-metal clasp dentures. Dent Mater J, 2010; 29:353-61.

25. Murray MD and Darvel BW. The evaluation of complete base. Theories of complete denture retention. A review part one. Aus Dent J. 1993;38-40. 